\title{
Susceptibility of different eukaryotic cell lines to SARS-coronavirus
}

\author{
Brief Report \\ K. Hattermann*, M. A. Müller*, A. Nitsche, S. Wendt, \\ O. Donoso Mantke, and M. Niedrig \\ Robert Koch-Institut, Center for Biological Safety 1, Berlin, Germany \\ Received September 16, 2004; accepted November 1, 2004 \\ Published online January 13, 2005 (C) Springer-Verlag 2005
}

Summary. In order to define and characterize target cells of SARS-coronavirus (SARS-CoV) we studied the susceptibility of 23 different permanent and primary eukaryotic cell lines to SARS-coronavirus. Beneath Vero E6 cells SARSCoronavirus infection could also be demonstrated in two pig cell lines (POEK, PS) and one human cell line (Huh-7) using the indirect immunofluorescence assay and a newly established quantitative real-time PCR. In all susceptible cell lines mRNA of the Angiotensin-converting enzyme 2 (ACE2), the functional receptor for SARS-CoV infection, could be detected by RT-PCR. Our results show that there is a correlation between the abundance of ACE2 mRNA and SARS-CoV susceptibility.

$*$

A novel coronavirus with a positive single-stranded RNA genome of approximately $30.000 \mathrm{bp}$ has been identified as the causative agent of severe acute respiratory syndrome (SARS) $[3,8]$. The SARS-coronavirus (SARS-CoV) infects the lower respiratory tract with patients presenting fever, dry cough, dyspnoea, headache and hypoxemia [7]. The disease spread rapidly from Southern China to more than 30 countries within a few weeks resulting in about 8.400 cases and 800 deaths [13]. The functional cellular receptor for SARS-CoV could recently be identified as the Angiotensin-converting enzyme 2 (ACE2) [9].

So far the reservoir of SARS-CoV has not yet been precisely clarified. The virus could be isolated out of palm civets (Paguma larvata), raccoon dogs (Nycereutes procyonoides) and other mammals that are for sale on live animal

*These authors contributed equally to this article. 
markets and sometimes eaten in China [2]. However, these species are not necessarily the natural hosts.

In our study we investigated if SARS-CoV could infect and replicate in permanent cell lines and primary cells of different species in order to i) define and characterize potential target cells of SARS-CoV, ii) to understand the mechanism of virus transmission and the nature and range of target cells and organisms. We furthermore investigated SARS-CoV susceptible and not-susceptible cell lines for ACE2 mRNA.

To study the kinetic of SARS-CoV infection, various cell lines were infected with SARS-CoV strain Hong Kong at multiplicities of infection (M.O.I.) of approximately 30 . The production of SARS-CoV was determined in the supernatant and in the infected cells at definite time points post infection using a quantitative real-time PCR [11]. In parallel, infected cells were investigated for the presence of viral protein using an indirect immunofluorescence assay (IFA) [5].

For stock production, SARS-CoV (strain 6109) isolated from a Hong Kong patient (kindly provided by Wilina Lim, Government Virus Unit Hong Kong) was added to Vero E6 cells (American Type Culture Collection, ATCC, CRL 1586). After $8 \mathrm{~h}$ of incubation the supernatant and the infected cells were harvested, stringently centrifuged $(10 \mathrm{~min}$ at $6000 \times \mathrm{g})$ and the supernatant was aliquoted. Afterwards the virus titre was determined $\left(3.25 * 10^{7} \mathrm{PFU} / \mathrm{ml}\right)$.

All cell lines used (Table 1) were grown in the appropriate culture medium recommended by ATCC or ECACC (European Collection of Cell Cultures). Porcine Peripheral Blood Mononuclear Cells (PBMC) were isolated from a healthy pig and grown in Roswell Park Memorial Institute 1640 Medium (RPMI 1640) (Gibco, Paisley, UK) with $10 \%$ FCS and $2 \mathrm{mM}$ glutamine (ICN, Costa Mesa) and $100 \mu \mathrm{g} / \mathrm{ml}$ streptomycin and $100 \mathrm{U} / \mathrm{ml}$ penicillin (Biochrom, Berlin, Germany). Chicken embryo fibroblasts were prepared from 11-day-old chicken embryos and cultivated in Dulbeccos Modified Eagle Medium (D-MEM) (Gibco, Paisley, UK) supplemented with $10 \%$ FCS and $100 \mu \mathrm{g} / \mathrm{ml}$ streptomycin and $100 \mathrm{U} / \mathrm{ml}$ penicillin.

One day before infection adherent cells were seeded onto sterile glass slides in 12-well plates while suspension cells were cultivated in 6-well plates. Adherent cells were infected with $25 \mu \mathrm{l}$ and suspension cells with $100 \mu \mathrm{l}$ of infectious supernatant of SARS-CoV $\left(3.25 * 10^{7} \mathrm{PFU} / \mathrm{ml}\right)$. Vero E6 cells were used as a positive control while uninfected cells were used as negative controls.

For quantitative real-time PCR RNA from approximately $2.5 * 10^{4}$ cells was prepared using the RNeasy Protect Mini Kit (Qiagen, Hilden, Germany). Similarly, infected cell supernatant was centrifuged at $1.000 \mathrm{rpm}$ in a Heraeus Varifuge to remove cells; RNA was extracted from $140 \mu 1$ supernatant using the QIAamp Viral RNA Mini Kit (Qiagen, Hilden, Germany). The amount of SARS-CoV RNA was determined in triplicate by quantitative real-time PCR as described elsewhere [11].

For RT-PCR analysis total RNA was isolated using RNeasy Protect Mini Kit (Qiagen) and was twice digested with DNase I (AMBION, Huntingdon, UK) as described in the manual instructions. For the detection of ACE2 mRNA, cDNA was produced from total RNA of all cell lines susceptible for SARS-CoV 
Table 1. List of cell lines used for the experiments

\begin{tabular}{|c|c|c|c|c|}
\hline Designation & Tissue & Source & Organism & Susceptibility \\
\hline Huh-7D12 & liver & ЕСАСС 01042712 & human & +++ \\
\hline Hep2 & liver & АTCC HB-8065 & human & + \\
\hline 293 & fetal kidney & ATCC CRL-1573 & human & - \\
\hline RH & kidney & $R K I^{1}$ & human & - \\
\hline Ma23 & lungfibroblast & $R K I$ & human & - \\
\hline Chang Liver & hela contaminant & ATCC CCl-13 & human & - \\
\hline RD & mouthcarcinoma & $R K I$ & human & - \\
\hline Wil2.NS.6TG & spleen & ЕСАСС 93031001 & human & - \\
\hline C8166 & t-lymphocyte & ЕСАСС 88051601 & human & - \\
\hline U937 & monocyte & ATCC CRL-1593.2 & human & - \\
\hline H9 & t-lymphocyte & АТСС НTB-176 & human & - \\
\hline Vero E6 & kidney & ATCC CRL-1586 & monkey & +++ \\
\hline $\mathrm{PBMC}^{2}$ & & Charite $^{3}$ & porcine & - \\
\hline POEK & fetal kidney & $R K I$ & porcine & ++ \\
\hline PS & kidney & $R K I$ & porcine & + \\
\hline PK & kidney & ATCC CCL-33 & porcine & - \\
\hline MDBK & kidney & ATCC CCL-22 & bovine & - \\
\hline PG-4 & fibroblasts & ATCC CRL-2032 & feline & - \\
\hline AK-D & lung & ATCC CCL-150 & feline & - \\
\hline FeT-J & t-lymphocyte & ATCC CRL-11967 & feline & - \\
\hline CTL-6 & fibroblasts & $R K I$ & murine & - \\
\hline RAT-2 & fibroblasts & $R K I$ & murine & - \\
\hline Embryo Fibroblasts & 11 day old embryo & $R K I$ & chicken & - \\
\hline
\end{tabular}

${ }^{1}$ RKI Robert Koch-Institut, Berlin, Germany

${ }^{2}$ PBMC Peripheral Blood Mononuclear Cells

${ }^{3}$ Charité, Berlin, Germany

${ }^{+++}$High infection rate; $50-100 \%$ of positive cells $31 \mathrm{~h}$ after infection determined by IFA

${ }^{++}$Moderate infection rate; less than $50 \%$ of positive cells $31 \mathrm{~h}$ after infection determined by IFA

${ }^{+}$Low infection rate; isolated cell infection $31 \mathrm{~h}$ after infection determined by IFA

- Negative cells $31 \mathrm{~h}$ after infection determined by IFA

and from some not-susceptible cell lines using the following protocol: $250 \mathrm{ng}$ of total RNA was reverse transcribed in $20 \mu \mathrm{l}$ volume with $250 \mathrm{ng}$ oligo dT primer (Fermentas, St. Leon-Rot, Germany), $20 \mathrm{nmol}$ dNTPs (Eppendorf, Hamburg, Germany), $40 \mathrm{U}$ RNasin (Promega, Mannheim, Germany), $4 \mu \mathrm{l} 5 \times$ buffer, $100 \mathrm{nmol} \mathrm{MgCl}_{2}, 200 \mathrm{nmol}$ DTT and $200 \mathrm{U}$ SuperScript II RT (Invitrogen, Karlsruhe, Germany). Before adding the enzymes the reaction mixture was heated to $65^{\circ} \mathrm{C}$ for $5 \mathrm{~min}$ and placed on ice for $1 \mathrm{~min}$. The program for the reverse transcription was $42^{\circ} \mathrm{C}$ for $50 \mathrm{~min}$ and $70^{\circ} \mathrm{C}$ for $15 \mathrm{~min}$. To check if the transcription has been successful and the transcribed RNA has been free of PCR inhibitors all human and simian cDNA samples were tested in a control PCR using primers detecting the glycerylaldehyde 3-phosphate dehydrogenase (GAPDH) 
gene [12]. Amplification was performed in a $25 \mu 1$ reaction volume using $1 \mu 1$ of cDNA, $2.5 \mu \mathrm{l} 10 *$ buffer, $5 \mathrm{nmol} \mathrm{dNTPs}, 75 \mathrm{nmol} \mathrm{MgCl}_{2}$, and $1 \mathrm{U}$ Taq Polymerase (Invitrogen, Karlsruhe, Germany) $\left(94^{\circ} \mathrm{C}, 2 \mathrm{~min} ; 35 *\left[94^{\circ} \mathrm{C}, 30 \mathrm{sec} ; 59^{\circ} \mathrm{C}\right.\right.$, $\left.\left.30 \mathrm{sec} ; 72^{\circ} \mathrm{C}, 1 \mathrm{~min}\right] 72^{\circ} \mathrm{C}, 3 \mathrm{~min}\right)$. The resulting PCR product had a length of $225 \mathrm{bp}$. Same PCR conditions were used for the amplification of ACE2 cDNA with primers ACE2 F 5' ${ }_{2}$ GCCCAACCCAAGTTCAAAG ${ }_{20}-3^{\prime}$ and ACE2 R $5^{\prime}$ ${ }_{170}$ CCTCAATGGTGGACTGAGCA $151-3^{\prime}$. Nucleotide positions refer to NCBI sequence GenBank accession no. NM021804 (human ACE2). The resultant PCR product of $168 \mathrm{bp}$ was sequenced and analyzed in BLAST.

SARS-CoV infected cells were cultivated for a total of $78 \mathrm{~h}$. At $0,7,31,55$ and $78 \mathrm{~h}$ after infection i) cell morphology was assessed by inspection with a light microscope for CPE diagnosis, ii) supernatant and cells were investigated for viral RNA load using the quantitative real time PCR, iii) cells were fixed and investigated for viral protein with the indirect immunofluorescence assay and analyzed by confocal laser scanning microscopy. Furthermore SARS-CoV susceptible and not-susceptible human cell lines were analyzed for mRNA of ACE2.

Analysis with a light microscope revealed CPE in Vero E6 cells starting $7 \mathrm{~h}$ after infection and in Huh-7 cells starting $31 \mathrm{~h}$ after infection. Vero E6 cells formed syncytia or progressed from typical elongated morphology to round dead cells with cell debris in the supernatant. By $55 \mathrm{~h}$ after infection almost all Vero E6 cells were detached from their support, whereas Huh-7 cells were still growing in monolayer and tended to syncytia formation. In contrast, no visible changes were observed in the porcine cells (data not shown).

IFA revealed that $7 \mathrm{~h}$ after infection viral protein could be detected in approximately 50\% (data not shown) and $31 \mathrm{~h}$ after infection in approximately $100 \%$ of the Vero E6 cells (Fig. 1/II A, B). In contrast, 50\% of the Huh-7 cells were positive for viral antigen not until $31 \mathrm{~h}$ after infection (Fig. 1/II C, D). At that time, the first presence of viral antigen could also be detected in porcine POEK (Fig. 1/II E, F) and in porcine PS cells (data not shown) but not in any of the other cell lines. However, compared to Vero E6 and Huh-7 cells (Fig. 1/II A and C) the number

Fig. 1. Detection of SARS-CoV RNA in supernatant and cell lysate of SARS-CoV infected cells and results of the indirect immunofluorescence assay. Detection of intracellular SARSCoV RNA (1/I A-C, grey line) and in the corresponding supernatant (1/I A-C, black line) of SARS-CoV-infected Vero E6 (1/I A), Huh-7 (1/I B) and POEK (1/I C) cells at different time points post infection (pi) using the quantitative real time PCR. Genome equivalents (ge) are given per 25,000 cells and per $5 \mu \mathrm{l}$ supernatant. Consider different scaling for the individual figures. Results of the indirect immunofluorescence assay $31 \mathrm{~h}$ after infection of Vero E6 (1/II A, B), Huh-7 (1/II C, D) and POEK cells (1/II E, F) with SARS-CoV Hong Kong $\left(3.25 * 10^{7} \mathrm{PFU} / \mathrm{ml}\right)$. The picture shown in $\mathbf{1} / \mathbf{I I} \mathbf{~ G}$ was taken after a 4 -week incubation of POEK cells with SARS-CoV Hong Kong ( $\left.3.25 * 10^{7} \mathrm{PFU} / \mathrm{ml}\right)$. Cells were analyzed with a confocal laser scanning microscope at a 100-fold magnification $(\mathbf{1} / \mathbf{I I} \mathbf{A}, \mathbf{C}, \mathbf{E}, \mathbf{G})$ and a 630-fold magnification (1/II B, D, F) respectively 

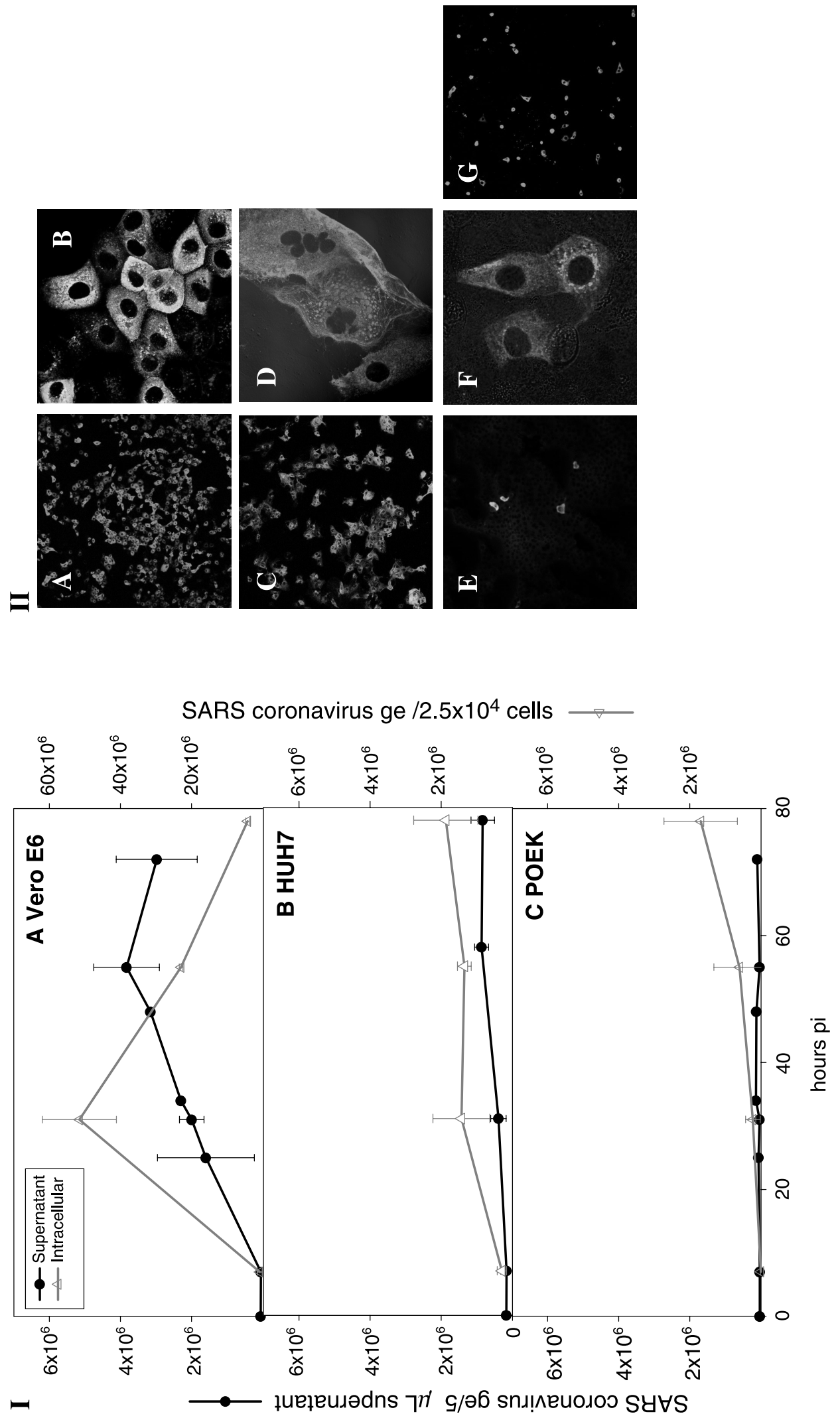
of SARS-CoV-positive porcine cells was low, despite of the same M.O.I. that had been used for the infection of all adherent cell lines.

The quantification of SARS-CoV RNA by quantitative real-time PCR revealed a significant increase of intracellular viral RNA in Vero E6, Huh-7, POEK, (Fig. 1/I A-C) and PS cells (data not shown). To determine whether extracellular virus particles had been produced by SARS-CoV infected human and porcine cells, cell-free supernatants were tested by quantitative real-time PCR at different times post infection. An increase of SARS-CoV RNA was detected in the supernatant of infected Vero E6, Huh-7, POEK (Fig. 1/I A-C) and PS cells (data not shown).

As expected, the investigation of all SARS-CoV susceptible cell lines (Vero E6, Huh-7, POEK and PS) for mRNA of ACE2 was positive in all cases though we failed to detect ACE2 expression by IFA, Western Blot and FACS analysis using commercially available monoclonal and polyclonal antibodies (ALPHA DIAGNOSTICS, San Antonio, USA) against human ACE2 (data not shown).

Although same amounts of cDNA were used and the experiments were repeated three times the signals of the porcine cell lines maintained much weaker (Fig. 2A lane 3 and 4). After sequencing, BLAST analysis of the resultant PCR products of SARS-CoV susceptible Vero E6 and Huh-7 cells showed a 98\% homology to the mRNA of the human ACE2 (GenBank accession no. NM021804), while porcine POEK and PS cells showed $87 \%$ homology to the mRNA of the human ACE2 (GenBank accession no. NM021804).

No mRNA of ACE2 could be detected in the not-susceptible cell lines (Fig. 2B). All cDNA samples used in the ACE2 PCR have been tested positive in the control PCR (Fig. 2C).

To examine whether the infection efficiency in porcine POEK could be increased by viral adaptation cells were infected with SARS-CoV Hong Kong as mentioned above and cultivated for 4 weeks. After this period of time the indirect immunofluorescence assay was carried out and SARS-CoV positive cells were counted. An adaptive effect resulting in a 10-fold higher infection rate could be observed in POEK cells (Fig. 1/II G).

In our studies we could demonstrate that the green monkey cell line Vero E6 and the human Huh-7 cells show a high susceptibility to SARS-CoV resulting in high infection rates within hours. Using the quantitative real-time PCR we could detect up to $6 * 10^{7}$ RNA copies in $2.5 * 10^{4}$ SARS-CoV infected Vero E6 cells $31 \mathrm{~h}$ after infection. These data could be confirmed with the IFA showing up to $100 \%$ infection of Vero E6 cells and 50\% infection of Huh-7 cells $31 \mathrm{~h}$ after infection. Another finding in our studies was the demonstration that SARS-CoV could replicate in porcine PS and POEK cells. These observations have also been made by others [4] who demonstrated replication of SARS-CoV in the porcine cell line PK-15. However, in our experiments infection rates of the porcine cells with SARS-CoV were clearly lower.

The Angiotensin-converting enzyme 2 has been identified to play an important role in SARS-CoV entry [9]. It can be expected that the SARS-CoV susceptible cells express a SARS-CoV specific receptor. We could identify mRNA of ACE2 
A

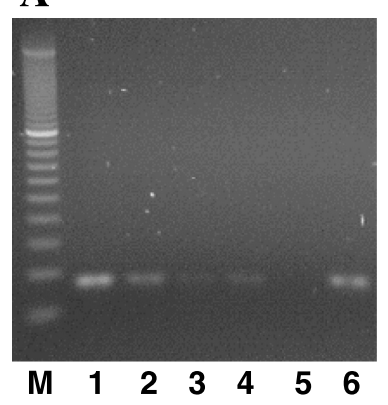

B

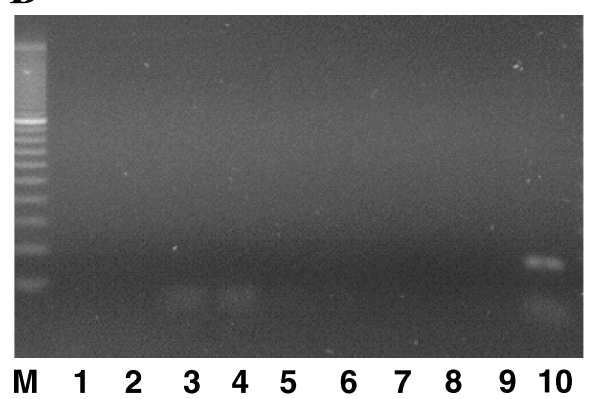

C

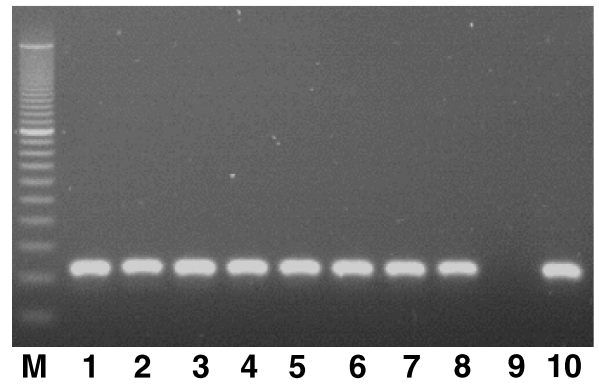

Fig. 2. Results of the ACE2 PCR (susceptible and not-susceptible cell lines). Results of the ACE2 PCR with cDNA transcribed from mRNA of SARS-CoV susceptible cells are given: $M$ Marker, 1 Vero E6, 2 Huh-7, 3 POEK, 4 PS cells; 5 shows the negative control while Vero E6 cDNA was used as a positive control (6). B shows the results of the ACE2 PCR after transcription of mRNA of some not-susceptible cell lines: $M$ Marker, 1 DNA of Chang liver, 2 MRC-5, 3 293, 4 U937, 5 Wil-2, 6 H9, 7 Hep2, 8 PG-4, negative control (9), positive control (10). The size of the fragment expected after amplification with primers ACE2 F/R was $168 \mathrm{bp}$. C shows the results of the GAPDH PCR from transcribed cDNAs of the above mentioned not-susceptible cell lines. Huh-7 cDNA was used as positive control

in SARS-CoV susceptible Vero E6, Huh-7, porcine POEK and PS cells but ACE2 protein expression could not be verified by several methods suggesting that the expression level may be very low. Recent studies have revealed that recombinant ACE2 expressed on the cell surface does trigger viral permissiveness and that infection can be blocked by soluble ACE2 [6, 10].

The different infection rates in porcine POEK and PS cells may be due to a lower expression rate of the ACE2 which we showed on mRNA level. Moreover there could be the necessity of an accessory factor for virus adsorption and entry. This could be confirmed by Chan et al. [1] who found ACE2 expression also in cells that were not susceptible for SARS-CoV.

Another possibility for lower infection rates in porcine cells may also be that the sequence homology of the human ACE2 strongly deviates from the porcine ACE2. Interestingly, infection efficiency in POEK cells could be increased quickly by adaptation of the virus to POEK cells. Present studies will therefore clarify the 
question to what extent the adapted viruses differ from the original virus stock by growth comparisons and sequencing.

\section{Acknowledgements}

This work was supported by the European Union (SPC. 20022396).

We thank Anette Teichmann and Inga Nehlmeier for excellent technical assistance. In addition we thank Dr. Stephen Norley for critically reading the manuscript and any helpful discussions.

\section{References}

1. Chan PK, To KF, Lo AW, Cheung JL, Chu I, Au FW, Tong JH, Tam JS, Sung JJ, Ng HK (2004) Persistent infection of SARS coronavirus in colonic cells in vitro. J Med Virol 74: 1-7

2. Cyranoski D, Abbott A (2003) Virus detectives seek source of SARS in China's wild animals. Nature 423: 467

3. Drosten C, Gunther S, Preiser W, van der Werf S, Brodt HR, Becker S, Rabenau H, Panning M, Kolesnikova L, Fouchier RA, Berger A, Burguiere AM, Cinatl J, Eickmann M, Escriou N, Grywna K, Kramme S, Manuguerra JC, Muller S, Rickerts V, Sturmer M, Vieth S, Klenk HD, Osterhaus AD, Schmitz H, Doerr HW (2003) Identification of a novel coronavirus in patients with severe acute respiratory syndrome. N Engl J Med 348: 1967-1976

4. Giroglou T, Cinatl J Jr, Rabenau H, Drosten C, Schwalbe H, Doerr HW, von Laer D (2004) Retroviral vectors pseudotyped with severe acute respiratory syndrome coronavirus $\mathrm{S}$ protein. J Virol 78: 9007-9015

5. Hattermann K, Maerz A, Slanina H, Schmitt C, Mankertz A (2004) Assessing the risk potential of porcine circoviruses for xenotransplantation: consensus primer-PCR-based search for a human circovirus. Xenotransplantation 11: 547-550

6. Hofmann H, Geier M, Marzi A, Krumbiegel M, Peipp M, Fey GH, Gramberg T, Pohlmann S (2004) Susceptibility to SARS coronavirus S protein-driven infection correlates with expression of angiotensin converting enzyme 2 and infection can be blocked by soluble receptor. Biochem Biophys Res Commun 319: 1216-1621

7. Hsu LY, Lee CC, Green JA, Ang B, Paton NI, Lee L, Villacian JS, Lim PL, Earnest A, Leo YS (2003) Severe acute respiratory syndrome (SARS) in Singapore: clinical features of index patient and initial contacts. Emerg Infect Dis 9: 713-717

8. Kuiken T, Fouchier RA, Schutten M, Rimmelzwaan GF, van Amerongen G, van Riel D, Laman JD, de Jong T, van Doornum G, Lim W, Ling AE, Chan PK, Tam JS, Zambon MC, Gopal R, Drosten C, van der Werf S, Escriou N, Manuguerra JC, Stohr K, Peiris JS, Osterhaus AD (2003) Newly discovered coronavirus as the primary cause of severe acute respiratory syndrome. Lancet 362: 263-270

9. Li W, Moore MJ, Vasilieva N, Sui J, Wong SK, Berne MA, Somasundaran M, Sullivan JL, Luzuriaga K, Greenough TC, Choe H, Farzan M (2003) Angiotensin-converting enzyme 2 is a functional receptor for the SARS coronavirus. Nature 426: 450-454

10. Moore MJ, Dorfman T, Li W, Wong SK, Li Y, Kuhn JH, Coderre J, Vasilieva N, Han Z, Greenough TC, Farzan M, Choe H (2004) Retroviruses pseudotyped with the severe acute respiratory syndrome coronavirus spike protein efficiently infect cells expressing angiotensin-converting enzyme 2. J Virol 78: 10628-10635

11. Nitsche A, Schweiger B, Ellerbrok H, Niedrig M, Pauli G (2004) SARS coronavirus detection. Emerg Infect Dis 10: 1300-1303 
12. Radonic A, Thulke S, Mackay IM, Landt O, Siegert W, Nitsche A (2004) Guideline to reference gene selection for quantitative real-time PCR. Biochem Biophys Res Commun 313: $856-862$

13. WHO (2003) Cumulative number of reported probable cases of SARS for the period 16 November 2002 to 7 August 2003. http://www.who.int/csr/sars/country/2003_08_15/en/

Author's address: Dr. Matthias Niedrig, Robert Koch-Institut, Center for Biological Safety 1, Nordufer 20, 13353 Berlin, Germany; e-mail: niedrigm@rki.de 